\title{
Applying Parametric Functional Approximations for Teaching Electromechanical Systems
}

\author{
J. Genaro González-Hernández ${ }^{1}$, Rubén Salas-Cabrera ${ }^{2}$, Carlos Soriano- \\ Rangel $^{3}$, E. Nacú Salas-Cabrera ${ }^{4}$ \\ ${ }^{I}$ Department of Mechatronics, Technological University of Altamira, Mexico \\ ${ }^{2,4}$ Division of Postgraduate Studies and Research, Madero Institute of Technology, Mexico \\ ${ }^{3}$ Department of Electrical Engineering, University of Denver Colorado, USA
}

\begin{abstract}
In this paper functional approximations for the parameters of a DC machine are proposed. These nonlinear algebraic approximations are based on the experimental data that are obtained by carrying out several steady state and transient tests, besides, this method links mathematics and practical analysis of electromechanical systems, allowing students to improve their academic performance and comprehension by comparing estimated values with measured data. An excellent dynamic model results of combining the well known state space description and these parametric functional approximations. This augmented model provides reliable results even during demanding large-excursion transient conditions.
\end{abstract}

Keywords: Electromechanical Systems, Academic Performance, Functional Approximations, TeachingLearning Process.

\section{Introduction}

When teaching electrical and electronics engineering dynamic systems at Mexican universities, it is very common that students get confused because there is a void between mathematics and electrical real world in teaching-learning process, so it is very important to appropriately established a link in order to help students the comprehension of concepts and to improve their academic performance [1-3]. In standard literature, several considerations are made in order to simplify the mathematical models describing actual dynamic systems and their operating conditions. However, these assumptions normally result in dynamic and steady-state errors. When these simplified models are used for implementing a closed loop system, then the controller have to deal with that lack of accuracy [4]. On the other hand, when these simplified models are employed for analysis, rigorous conclusions may be compromised due to the inaccuracies of the model.

It is standard to assume that the parameters involved in such mathematical descriptions remain constant during any operating condition. In practice, each one of the parameters depends on at least one particular state variable that is related to the actual transient and steady state operating conditions. In this work, several steady state and transient tests are performed on a shunt-connected DC machine in order to obtain some experimental data. These experimental results suggest that several types of nonlinear algebraic functions are necessary to describe of the parameters. Once the experimental data are obtained, an off-line calculation is carried out to derive the functional descriptions for all of the parameters. Models of these DC machines have been studied in the literature. For example in the seminal work [5] several models and methods to calculate the different parameters of a DC Servomotor are presented. However, these parameters are valid for certain operating conditions. All of the presented models are derived by considering several assumptions and neglecting some effects of the electric machine. In [4], a method is first proposed to classify the DC machine containing unknown parameters as one of the presented classes based on transient behavior, voltage and current readings; then the parameters are calculated by using the given equations.

Later in [6] a different yet very complex method to calculate the parameters of a DC Machine is proposed. This method is based on Genetic Algorithms; it demands extensive calculating operations and computer resources. Then in [7] another method that employs the Adaptive Tabu Search Technique is presented. Using a recursive method and experimental data, the parameters of a separately excited DC Motor are calculated.In this particular case, different experimental rotor speeds associated to several armature voltages are employed. However, the obtained parameters are constant for any operating condition.In [8] it was derived a method similar to the one presented in this paper, but with important differences regarding the results. In [8], a dynamometer and discrete readings are used to calculate the parameters. Using a Kalman Filter the angular acceleration is estimated and then utilizing a least-square algorithm accurate parameters are obtained. Later in [9], a separately excited DC motor is studied by employing a procedure called method of moments. The application of this method requires linearization which means that the obtained model and parameters will only be valid in the vicinity of the equilibrium point used to derive them. 
The main difference between all these results and ours relies on the mathematical description for the obtained parameters. In other words, these mentioned references result in constant parameters whilst our study derives nonlinear algebraic approximations that prove to be valid even during large scale transients. It is important to note that a brief description of the main result of this paper is presented as a part of work [10].

\section{Dynamic Modeling}

Let us consider (1) that defines the rotor speed of a DC machine where $\omega_{\mathrm{r}}$ is the rotor speed, $\mathrm{k}_{\mathrm{a}}$ is a constant defined by the design of the winding, $\phi$ is the direct-axis air gap flux, $\mathrm{i}_{\mathrm{a}}$ is the armature current, $\mathrm{T}_{\mathrm{L}}$ the load torque, $\mathrm{T}_{\text {loss }}$ the torque loss and $\mathrm{J}$ is the inertia.

$\frac{\mathrm{d} \omega_{\mathrm{r}}}{\mathrm{dt}}=\frac{\mathrm{k}_{\mathrm{a}} \phi \mathrm{i}_{\mathrm{a}}-\mathrm{T}_{\mathrm{L}}-\mathrm{T}_{\text {loss }}}{\mathrm{J}}$

In addition, the dynamics of the armature current is represented by (2), where $i_{a}$ is the armature current, $v_{a}$ is the voltage at the armature terminals, $\mathrm{L}_{\mathrm{AA}}$ is thearmature self-inductance and $\mathrm{r}_{\mathrm{a}}$ is the armature resistance.

$\frac{\mathrm{di}_{\mathrm{a}}}{\mathrm{dt}}=\frac{-\mathrm{k}_{\mathrm{a}} \phi \omega_{\mathrm{r}}}{\mathrm{L}_{\mathrm{AA}}}-\frac{\mathrm{r}_{\mathrm{a}} \mathrm{i}_{\mathrm{a}}}{\mathrm{L}_{\mathrm{AA}}}+\frac{\mathrm{v}_{\mathrm{a}}}{\mathrm{L}_{\mathrm{AA}}}$

Besides, the field current is defined by (3), where $\mathrm{i}_{\mathrm{f}}$ is the field current, $\mathrm{v}_{\mathrm{f}}$ is the voltage at the field terminals, $\mathrm{L}_{\mathrm{FF}}$ is the field self-inductance and $\mathrm{r}_{\mathrm{f}}$ is the field resistance.

$\frac{d i_{f}}{d t}=-\frac{r_{f} i_{f}}{L_{F F}}+\frac{v_{f}}{L_{F F}}$

\section{Functional Approximation}

This section deals with the description of the experimental tests necessary for deriving the nonlinear algebraic equations for the parameters.

\subsection{Direct-axis air gap flux}

The direct-axis air gap flux is normally associated to the field current. A standard assumption for the ideal DC machine is that magnetic saturation is neglected. In other words $\mathrm{k}_{\mathrm{a}} \phi=\mathrm{L}_{\mathrm{AF}} \mathrm{i}_{\mathrm{f}}$; where $\mathrm{L}_{\mathrm{AF}}$ is the mutual inductance between the armature and field windings. However, experimental data show a non-linear relationship between $\mathrm{k}_{\mathrm{a}} \phi$ and $\mathrm{L}_{\mathrm{AF}} \mathrm{i}_{\mathrm{f}}$ or equivalently between the armature voltage $\left(\mathrm{v}_{\mathrm{a}}\right)$ and field current $\left(\mathrm{i}_{\mathrm{f}}\right)$. It is important to note that the inductance $\mathrm{L}_{\mathrm{AF}}$ does not physically exist; it is used as a tool for representing a flux that appears in the armature winding as a result of a current flowing in the field winding.

In order to determine $\mathrm{k}_{\mathrm{a}} \phi$ as a function of the field current a standard experimental testis employed. This test consists of using the DC Machine as a generator coupled to a prime motor running at a constant angular speed. Different DC voltages are applied to the field winding of the DC Machine whereas the armature winding is left open. Since during this test the armature current $i_{a}=0$, and $\frac{\mathrm{di}_{\mathrm{a}}}{\mathrm{dt}}=0$, (2) can be rewritten as:

$k_{a} \phi=\frac{v_{a}}{\omega_{r}}$

This extensive experiment is carried out considering nine different angular speeds whereas different voltages are applied to the field winding. A set of experimental data is obtained for each one of the following experimental rotor speeds: 191, 391, 591, 792, 992, 1192 1391, 1491, and $1790 \mathrm{rpm}$.

During each test for a particular rotor speed, the steady state versions of the field current and armature voltage are measured.

Table 1 shows the experimental data obtained for a particular rotor speed $\left(\omega_{\mathrm{r}}=992 \mathrm{rpm}=103.882 \mathrm{rad} / \mathrm{s}\right.$. $)$. The $\mathrm{k}_{\mathrm{a}} \phi$ is clearly calculated by utilizing (4).

Table 1. Experimental data for $103.882 \mathrm{rad} / \mathrm{s}$.

\begin{tabular}{|l|l|l|l|}
\hline$v_{f}(\mathrm{~V})$ & $v_{a}(\mathrm{~V})$ & $i_{f}(\mathrm{~mA})$ & $k_{a} \phi(V s)$ \\
\hline 0 & 6.9 & 0 & 0.066422 \\
\hline 9.9 & 14.7 & 29 & 0.141507 \\
\hline 19.7 & 25.7 & 58 & 0.247396 \\
\hline 30.3 & 37.6 & 89 & 0.361949 \\
\hline 40.2 & 46.3 & 119 & 0.445698 \\
\hline 50.5 & 53.6 & 150 & 0.51597 \\
\hline 59.9 & 58.2 & 178 & 0.560251 \\
\hline 70.2 & 62.3 & 209 & 0.599719 \\
\hline 80.3 & 65.5 & 238 & 0.630523 \\
\hline 90 & 68 & 266 & 0.654589 \\
\hline 100.2 & 70.3 & 295 & 0.676729 \\
\hline 110.5 & 72.4 & 325 & 0.696945 \\
\hline 120.4 & 74 & 352 & 0.712347 \\
\hline
\end{tabular}


Each one of the experimental datum that is obtained for each one of the nine rotor speeds is depicted in Fig. 1 as an asterisk. It is clear that the relationship between direct-axis air gap flux and the field current suggests a square root function as it is shown in (5). Fig. 1 depicts both the experimental data and the corresponding data obtained by using the function-based representation given by Equation (5). In this investigation, a modified version of the rational function technique is employed for calculating the coefficients of the following functional approximation (see [11-13]).

$\mathrm{k}_{\mathrm{a}} \phi \cong 0.0099+1.2215 \sqrt{\left|\mathrm{i}_{\mathrm{f}}\right|}$

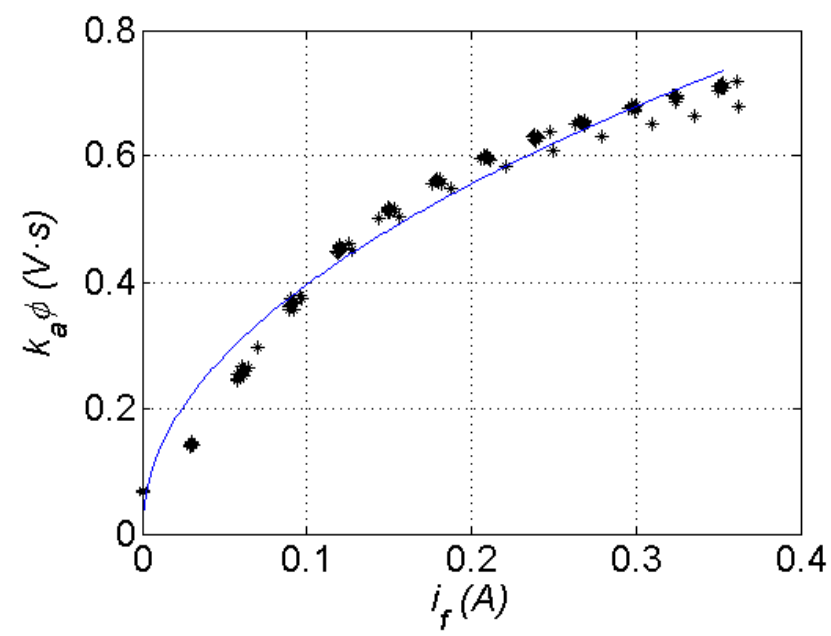

Fig. 1. $\mathrm{k}_{\mathrm{a}} \phi$ Experimental Data (*) and Functional Approximation (-).

\subsection{Field and armature resistance}

Field and armature resistance are obtained by utilizing a steady-state test. It consists of applying individually several DC voltages to each one of the windings and measuring the corresponding steady-state current. Then, the resistances are calculated by employing a basic fundamental law. The experimental data defines a parabolic-like behavior for both resistances as a function of the corresponding current. Using the least square method (see [14-15]), (6) and (7) are derived:

$\mathrm{r}_{\mathrm{f}} \cong 262.6 \cdot \mathrm{i}_{\mathrm{f}}^{2}+324.6772$

$\mathrm{r}_{\mathrm{a}} \cong 0.0788 \cdot \mathrm{i}_{\mathrm{a}}^{2}+7.5815$

Fig. 2 shows the experimental data and functional-based results for both resistances.
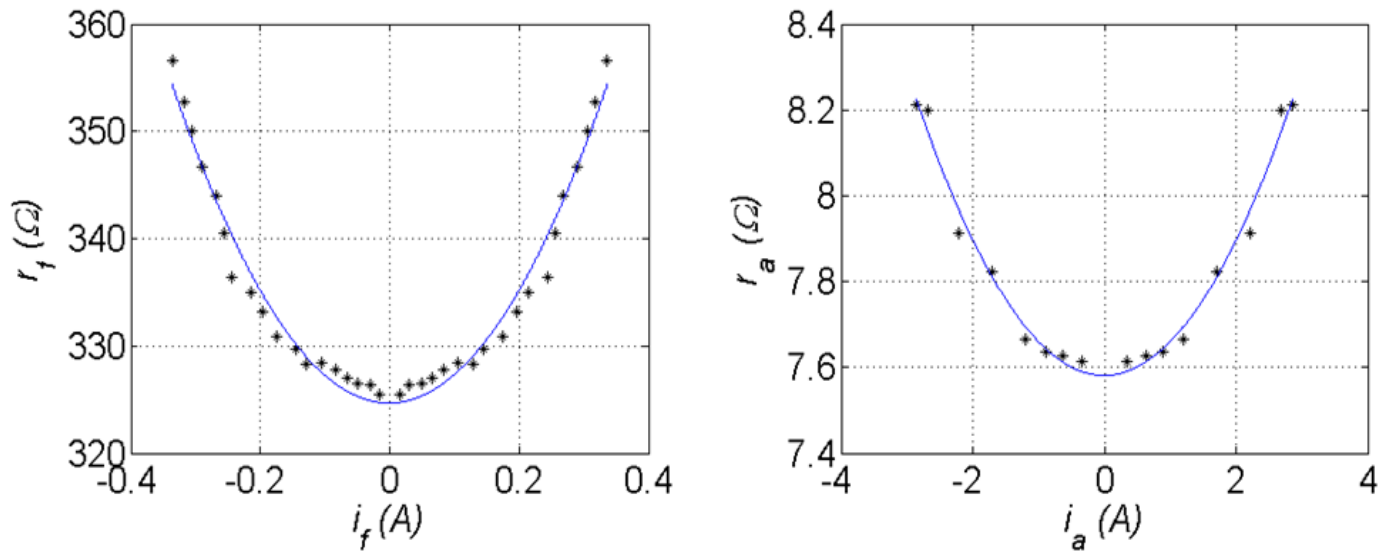

Fig. 2. Field and Armature Resistance. Experimental Data (*). Functional Approximation (-).

\subsection{Field and armature self-inductance}

A transient test is performed to determine the field self-inductance. A step of a DC voltage is applied at the winding terminals. The transient behavior of the current is recorded by employing a digital oscilloscope. On the other hand, it is well known the expression that represents the transient of a series-connected R-L circuit. In particular, the field current is defined as the response of an R-L circuit, i.e. (8).

$\mathrm{i}_{\mathrm{f}}=\frac{\mathrm{v}_{\mathrm{f}}}{\mathrm{r}_{\mathrm{f}}}\left[1-\mathrm{e}^{-\left(\frac{\mathrm{r}_{\mathrm{f}}}{\mathrm{L}_{\mathrm{FF}}}\right) \mathrm{t}}\right]$ 
The time constant (denoted by $\tau_{\mathrm{f}}$ ) is determined by observing the experimental trace of the current. Then, the corresponding field self-inductance can be calculated since the field resistance and the time constant are already known $\left(\mathrm{L}_{\mathrm{FF}}=\mathrm{r}_{\mathrm{f}} \tau_{\mathrm{f}}\right)$. During this test the armature winding is not powered up. The above test is carried out using different field voltages; therefore different values for the inductance are obtained.The armature self-inductance is determined by employing a similar transient test as the one described for the field selfinductance. In this case, the field winding is not powered up. The DC voltage is applied at the terminals of the armature. During this test the rotor speed is zero since the generated electric torque is not even enough for overcoming the start-up losses. Under these conditions, the rotational voltage that appears in Equation (2) as $\mathrm{k}_{\mathrm{a}} \phi \omega_{\mathrm{r}}$ is equal to zero. The resulting state equation for the armature current corresponds to a standard seriesconnected RL circuit, that is shown by (9).

$\frac{\mathrm{di}_{\mathrm{a}}}{\mathrm{dt}}=-\frac{\mathrm{r}_{\mathrm{a}} \mathrm{i}_{\mathrm{a}}}{\mathrm{L}_{\mathrm{AA}}}+\frac{\mathrm{v}_{\mathrm{a}}}{\mathrm{L}_{\mathrm{AA}}}$

Under the above conditions, the transient defined for the armature current is analogous to the one represented in (8) for the field current. Once that the experimental transient behavior of the armature current is recorded, the corresponding time constant (denoted by $\tau_{\mathrm{a}}$ ) can be determined. Now, the armature selfinductance can be calculated since the armature resistance and the time constant are already known $\left(\mathrm{L}_{\mathrm{AA}}=\right.$ $\left.\mathrm{r}_{\mathrm{a}} \tau_{\mathrm{a}}\right)$.

As the test for the field inductance, the armature test is performed utilizing different armature voltages; therefore different values for the inductance are obtained. The experimental data obtained for both the armature and field self-inductances show a behavior similar to that defined by a polynomial function depending on the square root of the current. Coefficients for the inductances' representations are calculated by utilizing the modified version of the rational function technique (see [6-8]), i.e. (10) and (11), where the absolute value is used to avoid the square root of a negative current.

$\mathrm{L}_{\mathrm{FF}} \cong 9.125+22.495 \sqrt{\left|\mathrm{i}_{\mathrm{f}}\right|}$

$\mathrm{L}_{\mathrm{AA}} \cong 5.323 \times 10^{-3}+22.972 \times 10^{-3} \sqrt{\left|\mathrm{i}_{\mathrm{a}}\right|}$

Field self-inductance and armature self-inductance are shown in Fig. 3, which depicts the experimental data and the calculated data by using the functional approximation given by (10) and (11).
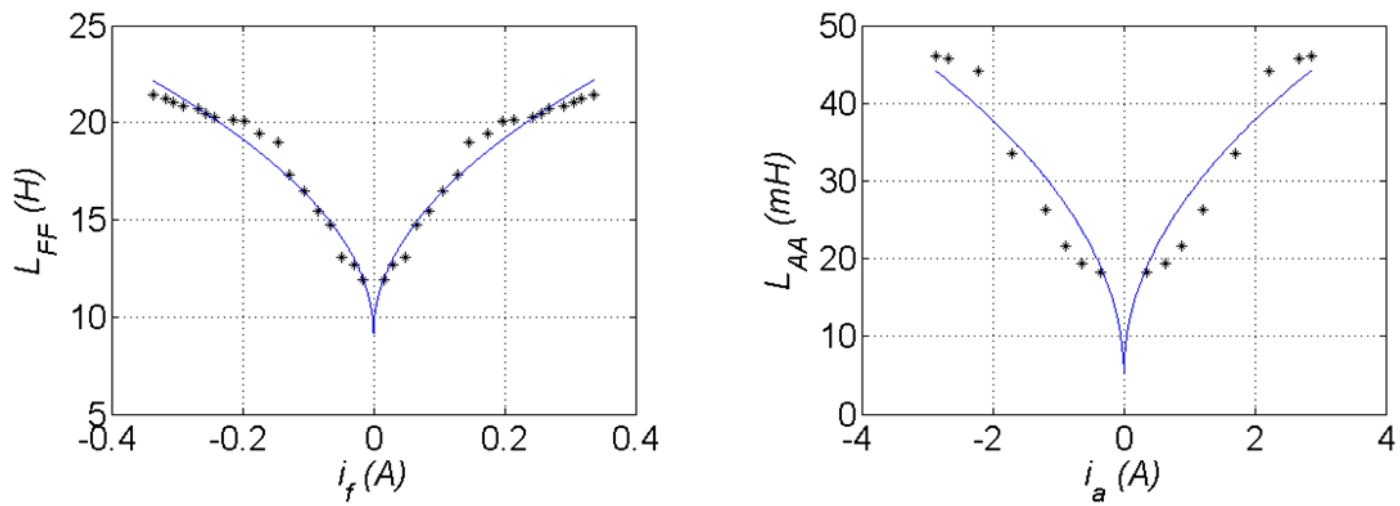

Fig. 3. Field and Armature Inductance. Experimental Data (*). Functional Approximation (-).

\subsection{Inertia}

The inertia is determined by employing the retardation test. During this experiment a DC voltage is applied to both the armature and field windings. There is no mechanical load connected to the shaft of the DC machine, that is $\mathrm{T}_{\mathrm{L}}=0$. With these assumptions, the steady state version of (1) may be written as (12), where $\mathrm{k}_{\mathrm{a}} \phi$ is defined by (5).

The description for $\mathrm{T}_{\text {loss }}$ that is based on (5) provides a better model than the representation based on the traditional linear model $\left(\mathrm{T}_{\text {loss }}=\mathrm{L}_{\mathrm{AF}} \mathrm{i}_{\mathrm{f}} \mathrm{i}_{\mathrm{a}}\right),(12)$ is also employed for calculating $\mathrm{T}_{\text {loss }}$ once the steady state values of the field and armature currents are measured.

$\mathrm{T}_{\text {loss }}=\mathrm{k}_{\mathrm{a}} \Phi \mathrm{i}_{\mathrm{a}}=\left(0.0099+1.2215 \sqrt{\left|\mathrm{i}_{\mathrm{f}}\right|}\right) \mathrm{i}_{\mathrm{a}}$

With the electric machine operating in a steady state condition, the armature voltage is removed. Under these conditions ( $\mathrm{i}_{\mathrm{a}}=0$ and $\mathrm{T}_{\mathrm{L}}=0$ ), the dynamics of the rotor speed can be derived from (1), resulting (13). $\frac{\mathrm{d}}{\mathrm{dt}} \omega_{\mathrm{r}}=-\frac{\mathrm{T}_{\text {loss }}}{\mathrm{J}}$

The transient rotor speed is then measured. It is the experimental version of the dynamics defined by (13). This measured trace is used for estimating its slope as an approximation of the derivative in (13). Then, the inertia can be calculated by rewriting the above equation, that is (14), where the suffix $\mathrm{m}$ refers to the slope calculated from the acquired experimental rotor speed. 
The experiment is conducted using different initial steady state rotor speeds corresponding to different armature voltages. The field voltage remains constant at its nominal value during this retardation test. The numerical results are presented in Table 2 .

$\mathrm{J}=\frac{\mathrm{T}_{\text {loss }}}{\left(\frac{\mathrm{T}_{\text {loss }}}{\mathrm{J}}\right)_{\mathrm{m}}}$

Table 2. Inertia for different rotor speeds.

\begin{tabular}{|l|l|l|l|}
\hline Initial rotor speed(rad/s) & $\mathrm{k}_{\mathrm{a}} \phi \mathrm{i}_{\mathrm{a}}(\mathrm{N} \mathrm{m})$ & Slope & Inertia $\left(\mathrm{kg} \mathrm{m}^{2}\right)$ \\
\hline 84 & 0.344298 & 5.259655964144001 & 0.06546019373411 \\
\hline 64 & 0.334260 & 5.075870504799103 & 0.06585274381684 \\
\hline 42 & 0.319404 & 4.896890799982390 & 0.06522587761220 \\
\hline 32 & 0.304548 & 4.800188348412709 & 0.06344501046520 \\
\hline
\end{tabular}

From Table 2, it can be noted that the maximum error of estimation of the inertia is about $2 \times 10^{-3} \mathrm{~kg} \mathrm{~m}^{2}$. Arithmetic mean of the set of values will be used as an estimation of the inertia. In Fig. 4, both the measured rotor speed and its simulated transient behavior are shown. The simulated trace is obtained by integrating (13) and using the estimated inertia.

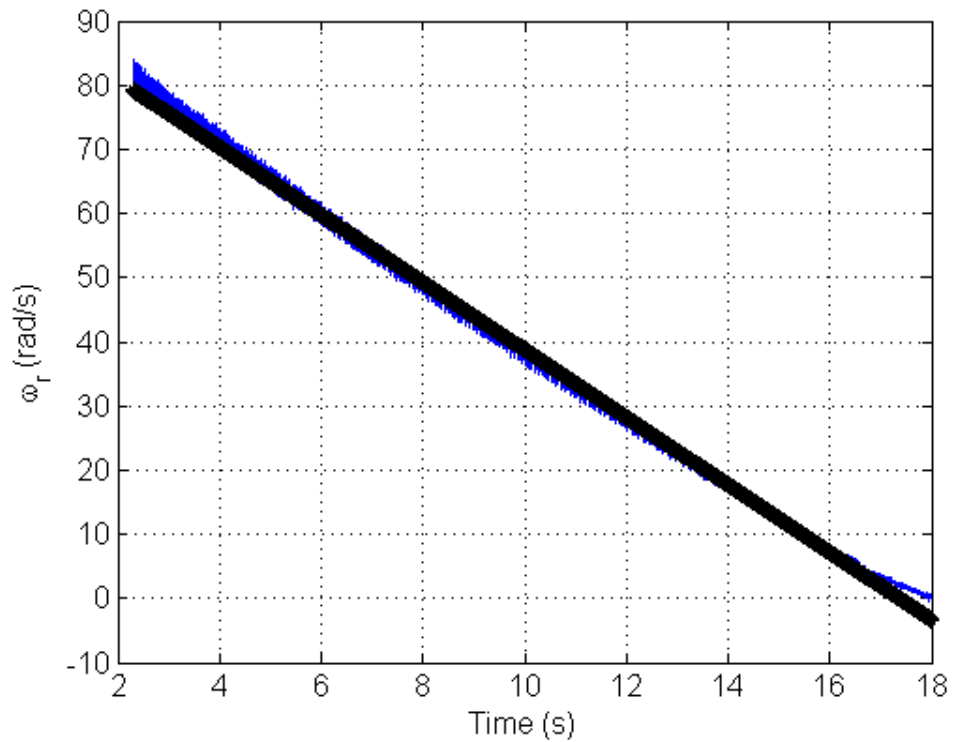

Fig. 4. Measured rotor speed (blue), simulated rotor speed using the estimated inertia (black)

\section{Findings And Comments}

The functional approximations of the parameters are used to validate the transient behavior of the state variables during a nonlinear dynamic test. The electric machine is initially stalled when armature and field voltages are applied simultaneously. Then, a random set of load torque steps is applied. These perturbations are large enough for producing a nonlinear large-excursion behavior of the state variables. During this test, transient values for the parameters occurred as the state variables vary. The experimental dynamics of the rotor speed, armature current and field current are measured. The DC motor is shunt connected; therefore the same voltage is applied to the field and armature windings. This voltage is also measured. For the purpose of measuring all of the variables, a hardware/software real time platform is used. The main components of this platform are: a personal computer containing a PCI Bus, a NI PCI-6024E data acquisition card and a free open source Linux distribution (Knoppix 5.0) including a real time patch [16]. Field and armature currents are measured by employing two Nana Electronics SHR-100 hall effect sensors [17].

An encoder and a custom-made microprocessor-based electronics design are used for measuring the dynamics of the rotor speed. During the experimental test, the dynamics of the load torque and torque loss are not measured; they are estimated by a nonlinear state affine observer. In order to compare experimental and simulated results the nonlinear dynamic state equations defined in expressions (1-3), they are numerically solved in a digital computer. The simulation also includes the mathematical description for the parameters given by (57) and (10-11). The same initial conditions for the experimental test and for the simulated model are established. Fig. 5 depicts the measured and simulated dynamics of the armature current. The initial peak of the armature current corresponds to the start-up current. The other peaks are due to the application of the steps of load torque. There are some periods of time in Figure 5 where a non-zero steady current appears. For example, there is a 
constant current between 5.5 and 6.5 seconds. This current is clearly associated to the electric power necessary for overcoming the torque loss. It can be seen that in spite of the large-excursion of the armature current, the augmented system (state equations + parametric expressions) proves to be a very accurate mathematical representation of the experimental system during transient and steady state conditions. There is no appreciable difference between the simulated and measured behavior.The importance of the trace depicted in Fig. 5 is related to the fact that the state equation of the armature current directly or indirectly depends on every state variable and their associated parameters.Significant parameter excursions occur during normal operation of the electric machine. For example, the armature self-inductance at the peak value of the start-up armature current can be as much as three times the armature self-inductance at zero armature current, i.e. $\mathrm{L}_{\mathrm{AA}}\left(\right.$ at $\left.\mathrm{i}_{\mathrm{a}}=3 \mathrm{amp}\right) \cong$ $3 \mathrm{~L}_{\mathrm{AA}}\left(\right.$ at $\left.\mathrm{i}_{\mathrm{a}}=0 \mathrm{amp}\right)$. It is important to recall that the standard full-order dynamic model for a shunt-connected DC machine is nonlinear. Normally, this standard dynamic model does not consider parametric variations. In our case, parametric variations are now defined by the nonlinear algebraic equations (5-7) and (10-11). If these improved mathematical descriptions for the parameters are substituted into the state equations (1-3), a new model with an increased nonlinearity is derived.

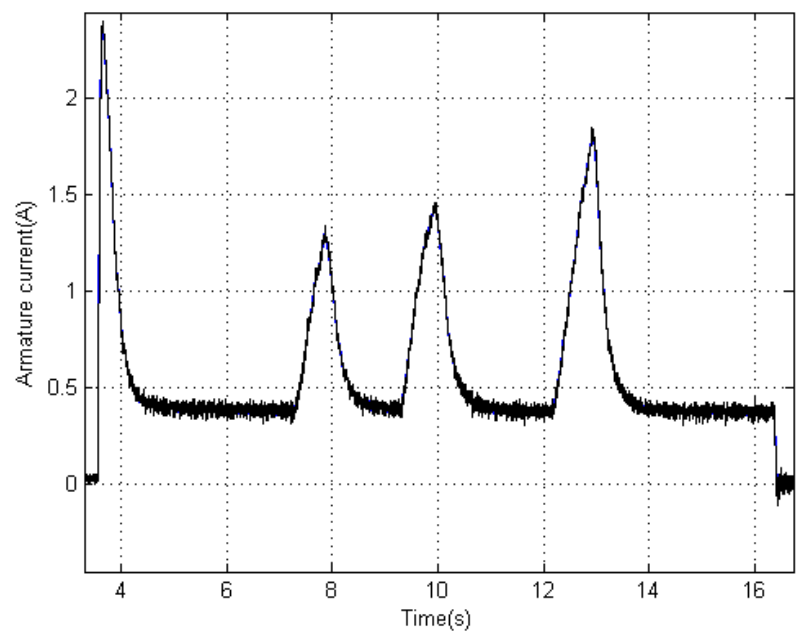

Fig. 5. Armature current.Measured (black), model based (blue)

\section{Conclusion}

In this work several nonlinear algebraic approximations are derived for describing the parameters behavior of a DC machine. The natural behavior of the parameters appears to suggest that these functional approximations are well behaved even during out of the range operation. A new nonlinear large-excursion dynamic model results of combining the standard nonlinear state space description and these parametric functional approximations. This detailed dynamic model can be employed for controller design and analysis. In the other hand, students were able to interpret that the results presented an important relationship between estimated and measured values, so they develop a whole vision of the system dynamic and improve their academic performance in the subject by linking numerical methods, electromechanical systems modeling and data acquisition. Table 3 shows results obtained by students who were thought by traditional Mexican universities class methods and those ones who were thought by proposed method.

Table 3. Averages of tests applied per indicator in each students group.

\begin{tabular}{|l|l|l|l|}
\hline \multirow{2}{*}{ Group } & \multicolumn{3}{|l|}{ Indicator of comprehension and application of concepts } \\
\cline { 2 - 4 } & System dynamics analysis & $\begin{array}{l}\text { Numerical methods } \\
\text { applications }\end{array}$ & $\begin{array}{l}\text { Electrical and electronics } \\
\text { global comprehension }\end{array}$ \\
\hline A (traditional method) & 64 & 61 & 75 \\
\hline B (proposed method) & 84 & 83 & 89 \\
\hline
\end{tabular}

\section{References}

[1] S.H. Priest, Linking theory and Practice, Science Communication, 30(1), 2008, 5-7.

[2] S. Gopalakrishnan, Linking Theory and Practice, Organization Management Journal, 5(1), 2008, 3-5.

[3] A. Vahed, S. Mc-Keena, and S. Singh, Linking the 'know that' and 'know how' knowledge through games: A quest to evolve the future for science and engineering education, Higher Education, 71(6), 2016, 781-790.

[4] R. Salas-Cabrera, J. Mayo-Maldonado, E. Rendon-Fraga, N. Salas-Cabrera, and A. Gonzalez-Rodriguez, On the experimental control of a separately exited DC motor, Lectures Notes in Electrical Engineering, Electronic Engineering and Computing Technology, 60 (Netherlands: Springer, 2010) 1-12.

[5] W. Lord, and A. H. Hwang, DC Servomotors-Modeling and Parameter Determination, IEEE Transactions on Industry Applications, 13(3), 1977, 234-243. 
[6] S. Cong, G. Li, and X. Feng, Parameters Identification of Nonlinear DC Motor Model Using Compound Evolution Algorithms, Proc. of the World Congress on Engineering, London, U.K., 2010, Vol. I. 978-988-17012-9-9/2078-0966.

[7] S. Udomsuk, K.L. Areerak, and K.N. Areerak, Parameters Identification of Separately Excited DC Motor using Adaptive Tabu Search Technique, International Conference on Advances in energy Engineering , Beijing, China, 2010, 978-960-474-208-0/17924324 .

[8] S. S. Saab, and R. A. Kaed-Bey, Parameter Identification of a DC Motor: An Experimental Approach, The 8th IEEE International Conference on Electronics, Circuits and Systems, Malta, 2001. Vol. II. 0-7803-7057-0.

[9] M. Hadef, A. Bourouina, and M. R. Mekideche, Parameter Identification of a DC Motor via Moments Method, Iranian Journal of Electrical and Computer Engineering, 7(2), 2008, 159-163.

[10] R. Salas-Cabrera, J. G. Gonzalez-Hernandez, J. de-Leon-Morales, J. C. Rosas-Caro, A. Gonzalez-Rodriguez, E. N. Salas-Cabrera, and R. Castillo-Gutierrez, Some Results on the Experimental Implementation of a State-Affine Observer for a DC Motor, Proc. World Congress on Engineering and Computer Science, San Francisco, USA, 2011,. 189-194.

[11] S. Nakamura, Numerical Analysis and Graphic Visualization with MATLAB (Upper Saddle River, New Jersey: Prentice Hall, 2001)

[12] H. Yongand, and T. Vincent, Updating Solutions of the Rational Function Model Using Additional Control Information, Photogrammetric Engineering \& Remote Sensing, 68(7), 2002, 715-723.

[13] R.X. Zeng, Modified rational function modeling for muti-port high-speed differential circuits, Microwave and Millimeter Wave Technology ICMMT International Conference, Nanjing, China, 2008, 459-462.

[14] W.Y. Yan, W. Cao, T-S Chung, and J. Morris, Applied Numerical Methods using MATLAB (Hoboken, New Jersey: Wiley, 2005).

[15] G.W. Recktenwald, Numerical Methods with MATLAB (Upper Saddle River, New Jersey: Prentice Hall, 2000).

[16] C. Negus, Linux 2011 Edition: Boot up to Ubuntu, Fedora, KNOPPIX, Debian, openSUSE, and 13th Other Distributions (Hoboken, New Jersey: Wiley, 2010).

[17] Nana Electronics Co., Ltd., SHR-100 Hall Effect Sensor Data Sheet (Tokyo, Japan: Nana Electronics Co., 1998). 